Original article

\title{
Relationships Between Current and Past Binge Drinking and Systolic Blood Pressure in Young Adults
}

\author{
Robert J. Wellman, Ph.D. ${ }^{a}$, John A. Vaughn, M.D. ${ }^{b}$, Marie-Pierre Sylvestre, Ph.D. ${ }^{c, d}$, \\ Erin K. O’Loughlin, M.A. ${ }^{\text {d,e }}$, Erika N. Dugas, M.Sc. d, and Jennifer L. O’Loughlin, Ph.D. ${ }^{\text {c, d, }}$, \\ ${ }^{a}$ Department of Family Medicine and Community Health, University of Massachusetts Medical School, Worcester, Massachusetts \\ ${ }^{\mathrm{b}}$ Student Health Service and Department of Community and Family Medicine, Duke University, Durham, North Carolina \\ ${ }^{\mathrm{c}}$ Department of Social and Preventive Medicine, University of Montréal, Montreal, Québec, Canada \\ ${ }^{\mathrm{d}}$ Centre de Recherche du Centre Hospitalier de l'Université de Montréal, Montreal, Québec, Canada \\ e INDI Department, Concordia University, Montreal, Québec, Canada
}

Article history: Received July 20, 2015; Accepted October 28, 2015

Keywords: Systolic blood pressure; Alcohol drinking; Young adult; Longitudinal studies

\section{A B S T R A C T}

Purpose: Heavy episodic (i.e., "binge") drinking (i.e., $\geq$ five drinks/occasion) is highly prevalent among young adults; those who binge do so four times per month on average, consuming nine drinks on average on each occasion. Although it is well established that chronic heavy drinking ( $\geq$ two alcoholic beverages per day) increases the risk of hypertension, the relationship between binge drinking and blood pressure is not well described. Our aim was to describe the relationship between frequency of binge drinking, both current (at age 24 years) and past (at age 20 years), and systolic blood pressure (SBP) at age 24 years.

Methods: Participants $(\mathrm{n}=756)$ from the longitudinal Nicotine Dependence in Teens study reported alcohol consumption at ages 20 and 24 years and had SBP measured at age 24 years. We examined the association between binge drinking and SBP using multiple linear regression, controlling for sex, race/ ethnicity, education, monthly drinking in high school, cigarette smoking, and body mass index.

Results: Compared to nonbinge drinkers, SBP at age 24 years was $2.61[.41,4.82] \mathrm{mm} \mathrm{Hg}$ higher among current monthly bingers and $4.03[1.35,6.70] \mathrm{mm} \mathrm{Hg}$ higher among current weekly bingers. SBP at age 24 years was $2.90[.54,5.25] \mathrm{mm} \mathrm{Hg}$ higher among monthly bingers at age 20 years and $3.64[.93,6.35] \mathrm{mm}$ Hg higher among weekly bingers at age 20 years, compared to nonbinge drinkers. Conclusions: Frequent binge drinking at ages 20 and 24 years is associated with higher SBP at age 24 years and may be implicated in the development of hypertension.

(c) 2016 Society for Adolescent Health and Medicine. All rights reserved.

\section{IMPLICATIONS AND CONTRIBUTION}

Little is known about the relationship between binge drinking and blood pressure (BP) in young adults. This study showed that frequency of binge drinking, past and present, is associated with higher systolic BP, which may pose a risk for developing hypertension. Practitioners should inquire about binge drinking when monitoring BP.
Numerous reports [1-3] suggest that alcohol consumption is associated with higher blood pressure (BP) and furthermore, that moderate to heavy drinking raises the risk of essential hypertension [4-6]. In cross-sectional analyses of CARDIA data for $>5,000$

\footnotetext{
Conflicts of Interest: The authors declare no conflicts of interest.

* Address correspondence to: Jennifer L. O'Loughlin, Ph.D., CRCHUM, 850 Saint-Denis (S02-370), Montreal, Quebec H2X 0A9, Canada.

E-mail address: jennifer.oloughlin@umontreal.ca (J.L. O’Loughlin).
}

US adults age 18-30 years, mean systolic BP (SBP) was directly associated with daily alcohol intake in white and black males and in white females [7]. Similarly, cross-sectional data for $>14,000$ adults (median age 29 years) participating in the 2008 wave of the National Longitudinal Study of Adolescent Health showed that consuming two drinks (females) or three drinks (males) on 5-7 days per week was associated with a $5.3 \mathrm{~mm} \mathrm{Hg}$ increase in SBP. Heavier drinking (i.e., $>$ two drinks (females) or $>$ three drinks (males) on 5-7 days per week) was associated with a $4.5 \mathrm{~mm} \mathrm{Hg}$ 
increase in SBP after controlling for body mass index (BMI) and smoking [8].

Variability in daily alcohol intake has rarely been investigated as a risk factor for high BP. INTERSALT, an international multicenter epidemiological study of 9,681 men and women, age 20-59 years, investigated the separate influence on BP of overall alcohol consumption and daily variability in consumption [9]. Overall, daily alcohol consumption was related to SBP. Compared to nondrinkers, SBP was $4.6 \mathrm{~mm} \mathrm{Hg}$ higher among men who consumed 6-7 drinks per day and $3.9 \mathrm{~mm} \mathrm{Hg}$ higher among women who consumed 3-4 drinks per day. SBP also tended to be higher than in nondrinkers among men and women who drank fewer than three drinks per day, but the differences were not statistically significant. Variability in daily drinking was independently associated with higher SBP. Compared to nondrinkers, SBP was $4.5 \mathrm{~mm} \mathrm{Hg}$ higher among men whose daily alcohol consumption was episodic and highly variable and who drank 3-4 drinks per day, on average and $2.2 \mathrm{~mm} \mathrm{Hg}$ higher among men who drank fewer than three drinks per day, on average, after controlling for age, BMI, and smoking [9].

Binge drinking (i.e., consuming $\geq$ five alcoholic beverages on a single occasion [10]) is associated with highly variable patterns of daily consumption and may be linked, over and above chronic heavy drinking, to higher BP. In a cross-sectional study of 14,000 adults age 45-69 years in Eastern Europe, compared to those who did not binge and those who binged (i.e., $\geq$ seven drinks for men and $\geq$ four drinks for women in one session) less than once/ month, men who binged at least once a month had a $62 \%$ greater likelihood and women a $31 \%$ greater likelihood of having hypertension (systolic $>140 \mathrm{~mm} \mathrm{Hg}$ and/or diastolic $>90 \mathrm{~mm} \mathrm{Hg}$ ) [11]. This effect was independent of annual alcohol intake.

Many young adults binge drink. Past-year prevalence estimates for $18-19$ year olds were $31 \%$ in the United States [10] and $43 \%$ in Canada [12], whereas estimates for 20-24 year olds were $45 \%$ in the United States [10] and 32\% in Canada [12]. Of particular concern is that 18- to 24-year-old binge drinkers report 4.2 binge drinking episodes per month on average, and they consume 9.3 drinks (approximately $126 \mathrm{~g}$ of pure ethanol [13]) on average per binge drinking occasion [14].

Although many studies explore the association between alcohol and chronic disease, the biological pathways leading from alcohol consumption to the early origins of chronic disease are not well understood. Given the dearth of studies investigating binge drinking as a risk factor for elevated BP and hypertension in young adults, our aim was to determine if current or past binge drinking is associated with SBP in a sample of young adults. We examined this objective in both cross-sectional and longitudinal analyses to broaden our understanding of the possible relationship between binge drinking and the development of hypertension.

\section{Methods}

Data were drawn from the prospective longitudinal Nicotine Dependence in Teens (NDIT) study conducted in Montréal, Canada [15]. A cohort of 1,294 students in grade 7, recruited in 1999 from 10 secondary schools, completed a self-report questionnaire at school every three months for a total of 20 surveys over the five years of secondary school (1999-2005). Schools were selected to include students from urban, suburban, and rural areas; from high, moderate and low socioeconomic status families; and who spoke either French and/or English. In two additional postsecondary school surveys, questionnaires were mailed to participants' homes in 2007-2008, when they were age 20 years on average; in 2011-2012 (age 24 years on average) questionnaires were completed and anthropometric and BP measurements were taken in the NDIT offices. Parents provided consent and participants provided assent during the secondary school cycles; participants provided consent in the postsecondary school surveys. The NDIT project was approved by the ethics research committee of the Centre de Recherche du Centre Hospitalier de l'Université de Montréal.

Characteristics of NDIT participants at baseline resembled those of a provincially representative sample of youth aged 13 years from the Quebec Child and Adolescent Health and Social Survey [15]. Between baseline (grade 7) and the final survey cycle in high school, 85 of the 1,294 baseline NDIT participants were lost to follow-up. An additional 130 participants refused followup after the first postsecondary school cycle (at age 20 years) [15, Table 2]. The second postsecondary cycle (at age 24 years) was completed by 858 participants (79.5\% of the 1,079 who remained eligible to participate at age 24 years); 781 of 858 provided BP measures [15; Table 2].

For the current analysis, we identified individuals whose SBP was measured at age 24 years and who provided data on the frequency with which they drank alcoholic beverages in the year preceding the measurement of BP (the "cross-sectional" analysis, so labeled because data on alcohol consumption and BP were collected at the same point in time). Most of those participants had also provided data on their alcohol consumption in the year preceding the survey at age 20 years (the "longitudinal" analysis, so labeled because frequency of alcohol consumption was measured four years before the BP measurements were taken).

\section{Study variables}

We chose SBP as the outcome measure because it is a stronger predictor of cardiovascular risk and leads to more accurate diagnosis and staging of hypertension than diastolic BP $[16,17]$. It has been suggested as the primary target of antihypertensive treatment [18]. SBP was assessed at age 24 years by trained technicians using standardized methods [19]. After the participant had voided and rested for 5 minutes, BP was assessed in the sitting position, on the right arm with the arm resting at heart height on a table, with an oscillometric device (Dinamap XL, model CR9340, Critikon Co, Tampa, FL). Cuff size (Brassard Baumanomètre) was determined by arm circumference: $16.0-22.5 \mathrm{~cm}$, size 9 (adolescent), $22.6-30.0 \mathrm{~cm}$, size 12 (adult), $30.1-37.5 \mathrm{~cm}$, size 15 (large adult), $37.6-43.7 \mathrm{~cm}$, size 17.5 (thigh). Oscillometric devices were calibrated against a mercury sphygmomanometer before each data collection period. Three consecutive measures were obtained at 1-minute intervals. If the difference between the second and third readings exceeded $20 \mathrm{~mm} \mathrm{Hg}$, then fourth and fifth readings were taken. To reduce BP reactivity or habituation, the first reading was not considered [20]. We calculated the mean of the two closest remaining readings.

We assessed alcohol consumption at age 20 years (labeled herein as "past drinking") and at age 24 years (labeled herein as "current drinking") with two questions: "During the past 12 months, how often did you drink alcoholic beverages?" and "During the past 12 months, how often did you drink 5 or more alcoholic beverages on one occasion?" Response options were never, <once a month, 1-3 times per month, 1-6 times per 
week, every day. The wording of the binge drinking question is similar to that used in the Canadian Addiction Survey ([12], p.21). Nondrinkers were defined as those who answered never to both questions, and nonbingers were defined as those who answered never to $\geq 5$ drinks per occasion but reported any frequency of drinking alcohol.

Covariates. The likelihood of engaging in binge drinking differs by sex, race/ethnicity, and level of education [14], and the risk of developing hypertension differs by socioeconomic status [21-24]. We, therefore, included self-reported sex, race/ ethnicity, and level of education as covariates, with education serving as a proxy for socioeconomic status.

In a previous NDIT study, drinking alcoholic beverages at least once per month in three or more years during high school predicted the likelihood of sustaining binge drinking between age 20 and 24 years [25]. Alcohol consumption was assessed in each of the 20 survey cycles during high school with the question "During the past three months, how often did you drink alcohol (beer, wine, hard liquor)?" Response options were never, a bit to try, once or a couple of times a month, once or a couple of times a week, usually every day. We calculated the number of grades $(0-5)$ in which a participant reported drinking at least once per month in any survey cycle. This was our measure of monthly drinking in high school.

Cigarette smoking is associated with higher SBP [26] in young adults [8] and adolescents [27]. We assessed smoking at age 24 years with two questions: "Have you ever in your life smoked a cigarette, even just a puff (drag, hit, haul)?" Ever smokers were asked "Did you smoke cigarettes, even just a puff, in the past three months?" Never smokers and ever smokers who had not smoked in the past three months were classified as nonsmokers, whereas past-three-month smokers were classified as smokers.

BMI is strongly associated with SBP [28]. Weight in kilograms and height in meters were measured at age 24 years by trained technicians using a standardized protocol [29]. We recorded two measures to the nearest $.2 \mathrm{~kg}$ for weight and $.1 \mathrm{~cm}$ for height. If they differed by $>.2 \mathrm{~kg}$ or $.5 \mathrm{~cm}$, a third measure was taken, and the average of the two closest measures was recorded. Inter-rater reliabilities (split-half coefficients) computed using repeat measures for one in 10 participants were .99 for both weight and height [30]. BMI was calculated according to the standard formula, weight $(\mathrm{kg}) /$ height $^{2}(\mathrm{~m})$.

\section{Statistical analyses}

We used t-tests, chi-square tests, and analyses of variance with Scheffé post hoc tests to examine bivariate relationships between SBP, frequency of current and past binge drinking, and the covariates. We then used multivariate linear regression analyses controlling for sex, racial/ethnic background, education, monthly drinking in high school, cigarette consumption, and BMI; variables were entered simultaneously. Possible multicollinearity between covariates was assessed with values of the variance inflation factor (VIF) $>2.5$ [31]. Following Stevens' recommendations [32], we identified potential outliers and influential data points with three measures: (1) Weisberg's $t$ for the studentized residual [33] $>3.92$ (the critical value for $p<.05$ with 11 predictors and $\mathrm{n}=500)$; (2) centered leverage scores $\left(h_{i i}\right)$ greater than twice the mean; and (3) Cook's distance [34] >1 [32]. Statistical analyses were conducted with IBM SPSS version
22 (released 2013, SPSS Statistics for Windows; IBM Corp., Armonk, NY).

\section{Results}

The analytic sample included 756 NDIT participants who had their SBP measured and provided data on their past-year alcohol consumption at age 24 years. Compared to the 538 NDIT participants not retained in the analyses, those retained were more likely to be female and less likely to have ever smoked a cigarette; they also reported having consumed fewer cigarettes in the three months preceding the survey. Their SBP and diastolic blood pressure were lower. There were no differences in race/ethnicity, parents' education, alcohol use, or BMI (Table 1). Data on past (age 20 years) alcohol consumption were missing for 65 participants. They did not differ from the 691 participants who provided data on SBP, current (age 24 years) alcohol consumption, sex, education, high school drinking, current smoking status, or BMI. However, they were more likely to be Caucasian (92.3\% vs. $81.9 \%$ ) than non-Caucasian $\left(\chi^{2}(1)=4.49, p=.03\right.$ ).

Mean age was 24 years (standard deviation $[S D]=.7$, range: 22.2-27.8); 54.6\% of participants were female. Most participants were Caucasian (82.8\%), followed by Asian (6.3\%), mixed/other (4.2\%), black (3.4\%), Arab (1.9\%), and Latin American (1.5\%). About half $(54.2 \%)$ of participants had some college or university education, $33.6 \%$ had attended or completed technical school or junior college, and $12.2 \%$ had a high school education. Mean SBP was 108.4 ( $\mathrm{SD}=11.5$, range: $81-149.5) \mathrm{mm} \mathrm{Hg}$.

Table 2 presents the results of the bivariate analyses. Among current weekly binge drinkers, mean SBP was $6.5[3.8,9.2] \mathrm{mm}$ $\mathrm{Hg}$ higher than among nondrinkers, $8.2[6.3,10.1] \mathrm{mm} \mathrm{Hg}$ higher than among nonbingers, and $6.7[5.2,8.2] \mathrm{mm} \mathrm{Hg}$ higher than among less than monthly bingers. Additionally, among current monthly bingers, mean SBP was $4.6[2.7,6.5] \mathrm{mm} \mathrm{Hg}$ higher than among nonbingers. Current monthly and weekly binge drinkers were more likely to meet the current criterion for a diagnosis of prehypertension (i.e., SBP > 120) [35] than were nondrinkers and nonbingers. Mean SBP in males was $11.3[9.8,12.7] \mathrm{mm} \mathrm{Hg}$ higher than in females. Compared to participants whose BMI was $<25$, mean SBP was $6.1[5.1,7.0] \mathrm{mm} \mathrm{Hg}$ higher among those whose BMI was 25-29.9 and 4.8 [3.9, 5.8] $\mathrm{mm} \mathrm{Hg}$ higher among those whose BMI was $\geq 30$.

In the cross-sectional multivariate model that used current binge drinking as the exposure (Table 3), SBP was $2.6 \mathrm{~mm} \mathrm{Hg}$

\section{Table 1}

Comparison of selected baseline characteristics of participants retained in the analyses and those not retained $(\mathrm{n}=1,294)$

\begin{tabular}{lccc}
\hline Characteristics & $\begin{array}{c}\text { Retained } \\
(\mathrm{n}=756)\end{array}$ & $\begin{array}{l}\text { Not retained } \\
(\mathrm{n}=538)\end{array}$ & $p^{\mathrm{a}}$ \\
\hline Age, mean years (SD) & $12.7(.5)$ & $12.9(.7)$ & $<.001$ \\
Male, \% & 45.4 & 52.1 & .016 \\
Caucasian, \% & 81.3 & 85.4 & .20 \\
Parents university educated, \% & 59.4 & 52.6 & .053 \\
Ever smoked, even just a puff, \% & 27.8 & 38.0 & $<.001$ \\
Number of cigarettes in past & $6.1(44.7)$ & $13.9(70.4)$ & .018 \\
$\quad 3$ months, mean (SD) & & & .32 \\
Drinks alcohol, \% & 41.8 & 44.7 & .019 \\
Systolic blood pressure, mean mmHg (SD) & $104.6(9.9)$ & $106.1(10.7)$ & .001 \\
Diastolic blood pressure, mean mmHg (SD) & $55.9(6.2)$ & $57.6(6.3)$ & $<.001$ \\
Body mass index, mean (SD) & $19.9(3.9)$ & $20.3(3.8)$ & .067 \\
\hline SD = standard deviation. & & & \\
a From $t$-tests and chi-square tests. & & &
\end{tabular}


Table 2

Bivariate relationships between alcohol consumption, covariates, and systolic blood pressure

\begin{tabular}{|c|c|c|c|}
\hline & $\mathrm{N}$ & SBP, M (SD) & $\mathrm{SBP}>120, \%$ \\
\hline \multicolumn{4}{|c|}{ Current (age 24 years) alcohol consumption ${ }^{a}$} \\
\hline Did not drink & 54 & $106.9_{\mathrm{b}}(9.9)$ & $5.6 \mathrm{y}$ \\
\hline Did not binge & 123 & $105.1_{\text {bd }}(10.7)$ & $8.9 y$ \\
\hline Binged $<$ monthly & 229 & $106.7_{\mathrm{b}}(11.5)$ & $14.4_{\mathrm{xy}}$ \\
\hline Binged monthly & 243 & $109.7 \mathrm{ac}(11.6)$ & $17.7_{\mathrm{x}}$ \\
\hline Binged weekly & 107 & $113.4_{a}(11.1)$ & $23.4 \mathrm{x}$ \\
\hline \multicolumn{4}{|l|}{ Sex } \\
\hline Male & 343 & $114.5_{\mathrm{a}}(11.5)$ & $29.7 x$ \\
\hline Female & 413 & $103.3_{\mathrm{b}}(8.6)$ & $3.1_{\mathrm{y}}$ \\
\hline \multicolumn{4}{|l|}{ Race/ethnicity } \\
\hline Caucasian & 618 & $108.5(11.7)$ & 16.0 \\
\hline Non-Caucasian & 128 & $107.8(10.8)$ & 11.7 \\
\hline \multicolumn{4}{|l|}{ Education } \\
\hline$<$ University & 346 & $108.5(11.5)$ & 15.0 \\
\hline University & 410 & $108.3(11.5)$ & 15.4 \\
\hline \multicolumn{4}{|c|}{ Monthly drinking in high school (years) } \\
\hline$\leq 2$ & 429 & $108.2(11.5)$ & 13.5 \\
\hline$\geq 3$ & 327 & $108.6(11.5)$ & 17.4 \\
\hline \multicolumn{4}{|c|}{ Cigarette smoking in past 3 months } \\
\hline No & 443 & $108.1(11.2)$ & 15.3 \\
\hline Yes & 303 & $108.7(11.8)$ & 15.2 \\
\hline \multicolumn{4}{|l|}{ BMI } \\
\hline$<25$ & 490 & $106.4_{\text {bd }}(10.7)$ & $10.6_{y}$ \\
\hline $25-29$ & 184 & $112.4 \mathrm{ac}(12.0)$ & $24.5 \mathrm{x}$ \\
\hline$\geq 30$ & 82 & $111.2_{\mathrm{a}}(12.1)$ & $22.0_{x}$ \\
\hline \multicolumn{4}{|c|}{ Past (age 20 years) alcohol consumption ${ }^{\mathrm{a}}$} \\
\hline Did not drink & 59 & $106.1_{a}(11.5)$ & $11.9_{\mathrm{xy}}$ \\
\hline Did not binge & 99 & $105.1_{\text {bd }}(9.6)$ & $8.1_{\mathrm{y}}$ \\
\hline Binged $<$ monthly & 191 & $106.8_{\mathrm{b}}(11.3)$ & $13.6_{\mathrm{xy}}$ \\
\hline Binged monthly & 231 & $109.7 \mathrm{ac}(11.8)$ & $17.3_{\mathrm{x}}$ \\
\hline Binged weekly & 111 & $111.1_{\mathrm{a}}(11.0)$ & $18.9 \mathrm{x}$ \\
\hline
\end{tabular}

$\mathrm{BMI}=$ body mass index $\mathrm{M}=$ mean; $\mathrm{SBP}=$ systolic blood pressure; $\mathrm{SD}=$ standard deviation.

a Refers to alcohol consumption in the 12 months preceding the survey (i.e., past-year consumption). In regard to each exposure, means (proportions) that do not share a subscript differ at $p<.05$ according to Scheffé post hoc comparisons or $\chi^{2}$ tests; multiple subscripts in regard to a mean reflect separate pairwise comparisons.

higher in monthly bingers and $4 \mathrm{~mm} \mathrm{Hg}$ higher in weekly bingers compared to nonbingers. VIF values were all $\leq 2.1$, indicating no multicollinearity. Eighteen cases had high leverage scores. However, the maximum Cook's distance was .03, so all cases were retained in the analysis.

In the bivariate analysis of past (age 20 years) binge drinking (Table 2), mean SBP among weekly binge drinkers was 5.0 [2.0, 8.0] $\mathrm{mm} \mathrm{Hg}$ higher than among nondrinkers and $6.0[4.1,7.9] \mathrm{mm}$ $\mathrm{Hg}$ higher than among nonbingers; among monthly binge drinkers mean SBP was $4.6[2.7,6.5] \mathrm{mm} \mathrm{Hg}$ higher than among nonbingers. More monthly and weekly binge drinkers than nonbingers met the criterion for a diagnosis of prehypertension.

In the longitudinal multivariate model that used past (age 20 years) binge drinking as the exposure (Table 4), SBP was almost $3 \mathrm{~mm} \mathrm{Hg}$ higher among monthly bingers at age 20 years and $3.6 \mathrm{~mm} \mathrm{Hg}$ higher among weekly bingers compared to nonbingers. VIF values were all $<2.3$, indicating no multicollinearity. Nine cases had high leverage scores. However, the maximum Cook's distance was .03, so all cases were retained in the analysis.

In a secondary analysis, we compared participants who reported past and current binge drinking (i.e., at age 20 and 24 years $(\mathrm{n}=458))$ with those who binged at age 20 years only $(\mathrm{n}=64)$. Mean SBP was 109.5 (SD = 11.5) among those who binged at both ages, compared to 105.2 ( $\mathrm{SD}=11.6$ ) among those who did not
Table 3

Unstandardized regression coefficients and 95\% confidence intervals from multivariate linear regression modeling the association between current (age 24 years) alcohol consumption and systolic blood pressure $(\mathrm{n}=736)$

\begin{tabular}{lc}
\hline Variable & $\begin{array}{l}\text { Unstandardized } \\
\text { coefficient }(95 \% \mathrm{CI}), p\end{array}$ \\
\hline Did not drink (Ref: did not binge) & $-.02(-3.23,3.19), .99$ \\
Binged < monthly & $.65(-1.54,2.83), .56$ \\
Binged monthly & $\mathbf{2 . 6 1}(. \mathbf{4 1}, \mathbf{4 . 8 2}), .020$ \\
Binged weekly & $\mathbf{4 . 0 3}(\mathbf{1 . 3 5 , 6 . 7 0}), .003$ \\
Sex (Ref: male) & $-\mathbf{1 0 . 0 4}(-\mathbf{1 1 . 5 4},-\mathbf{8 . 5 4}),<.001$ \\
Racial/ethnic background (Ref: Caucasian) & $.01(-1.90,1.88), .99$ \\
Education (Ref: no university) & $-.52(-1.96, .92), .48$ \\
Monthly drinking in high school & $.02(-1.42,1.45), .98$ \\
$\quad$ (years) (Ref: $\leq 2)$ & $.24(-1.22,1.69), .75$ \\
Cigarette smoking in past & \\
$\quad 3$ months (Ref: no) & $\mathbf{. 4 6}(. \mathbf{3 0}, \mathbf{6 2}),<.001$ \\
Body mass index & \\
$\mathrm{R}=.53$, adjusted $\mathrm{R}^{2}=.28$ & \\
\hline
\end{tabular}

(1) "Current alcohol consumption" refers to drinking during the 12 months preceding the survey at age 24 years. (2) Twenty participants had missing data on one or more covariates and were excluded from the analysis. (3) Variables were entered simultaneously. (4) Statistically significant coefficients are indicated in bold type.

$\mathrm{CI}=$ confidence interval; Ref $=$ reference

a Entered as a continuous variable.

$[t(520)=2.79, p=.005]$. However, this difference was not statistically significant after controlling for covariates (regression coefficient $=2.50[-.23,5.23], p=.07$ ), which may relate to a lack of statistical power because very few binge drinkers reported binge drinking at age 20 years only.

\section{Discussion}

In this study, we showed that frequency of binge drinking (whether current or past) is associated with higher SBP. These results concur with findings from the CARDIA study [7], the National Longitudinal Study of Adolescent Health [8], and

\section{Table 4}

Unstandardized regression coefficients and 95\% confidence intervals from multivariate linear regression modeling the association between past (age 20 years) alcohol consumption and systolic blood pressure $(n=673)$

\begin{tabular}{lc}
\hline Variable & $\begin{array}{l}\text { Unstandardized } \\
\text { coefficient }(95 \% \mathrm{CI}), p\end{array}$ \\
\hline Did not drink (Ref: did not binge) & $-.95(-4.16,2.27), .57$ \\
Binged $<$ monthly & $.79(-1.63,3.20), .52$ \\
Binged monthly & $\mathbf{2 . 9 0}(. \mathbf{5 4 , 5 . 2 5}), .016$ \\
Binged weekly & $\mathbf{3 . 6 4}(. \mathbf{9 3}, \mathbf{6 . 3 5}), .009$ \\
Sex (Ref: male) & $-\mathbf{1 0 . 1 4}(-\mathbf{1 1 . 6 6},-\mathbf{8 . 6 1}),<.001$ \\
Racial/ethnic background (Ref: Caucasian) & $.15(-1.79,2.09), .88$ \\
Education (Ref: no university) & $-.46(-1.97,1.04), .55$ \\
Monthly drinking in high school & $.17(-1.33,1.66), .83$ \\
$\quad$ (years) (Ref: $\leq 2)$ & $.34(-1.17,1.86), .66$ \\
Cigarette smoking in past & \\
$\quad 3$ months (Ref: no) & $\mathbf{. 4 6}(. \mathbf{3 0}, .63),<.001$ \\
Body mass index & \\
$\mathrm{R}=.53$, adjusted $\mathrm{R}^{2}=.27$ & \\
\hline
\end{tabular}

(1) "Past alcohol consumption" refers to drinking during the 12 months preceding the survey at age 20 years. (2) Eighteen participants had missing data on one or more covariates and were excluded from the analysis. (3) Variables were entered simultaneously. (4) Statistically significant coefficients are indicated in bold type.

$\mathrm{CI}=$ confidence interval; Ref $=$ reference.

a Entered as a continuous variable. 
the HAPIEE study [11], all of which found that the intensity of current drinking was associated with higher BP. Our study adds to these other studies by investigating both current and past drinking and by focusing specifically on binge drinking in young adults.

We previously reported that $85 \%$ of NDIT participants who binged at age 20 years sustained that behavior until at least age 24 years [25]. Although binge and heavy drinking generally decrease with age $[10,12]$, a review of six longitudinal studies conducted in the United States, Britain, and Finland found that drinking patterns in early adulthood were strong predictors of both frequency of alcohol use and problem drinking at ages 30 and 48 years [36]. If binge drinking is indeed associated with SBP, young adulthood may represent a critical period in the life course for the prevention of hypertension because drinking patterns are modifiable. Future research should examine the association between binge drinking and SBP in adolescence to determine how early in life the association is established.

As a speculative exercise, we estimated the potential increase in SBP associated with binge drinking from age 20 to 24 years by dividing the differences in SBP between frequent (monthly and weekly) binge drinkers and nonbingers by four years. Compared to drinking alcohol without binging, binging at least once per month at age 20 years might be associated with an increase of approximately $.75 \mathrm{~mm} \mathrm{Hg}$ per year and binging at least once per week with an increase of approximately $.90 \mathrm{~mm}$ Hg per year by age 24 years. The plausibility of this hypothesis is strengthened by our finding of a $4 \mathrm{~mm} \mathrm{Hg}$ difference (unadjusted for covariates) in SBP after four years among those who binged at age 20 and 24 years relative to those who binged at age 20 years only. If participants continued to binge at similar frequencies, and if the effects of binging were cumulative, their SBP could increase another 7.5-9 $\mathrm{mm} \mathrm{Hg}$ in the next 10 years, which could place many at risk of hypertension. This speculation is further reinforced by the significantly greater proportions of monthly and weekly past and current binge drinkers who qualified for a diagnosis of prehypertension compared to nonbinge drinkers. Because we measured SBP only once, we cannot determine the extent to which SBP changes over time. Future research should follow young adults with more frequent measurement of SBP and drinking to study whether binge drinkers develop hypertension more quickly than nondrinkers and nonbingers.

\section{Limitations}

Limitations of this study include that self-reports of alcohol consumption may have resulted in misclassification. Definitions of binge drinking differ. Although the US Substance Abuse and Mental Health Association defines binge drinking as "consuming five or more alcoholic drinks on the same occasion on at least one day in the past 30 days," the National Institute on Alcohol Abuse and Alcoholism provides a specific blood alcohol concentration (i.e., $\geq .08$ gram-percent) achieved within a specific time frame for a drinking occasion (i.e., about two hours) and a different amount for men (five drinks) and women (four drinks) [37]. Because our definition of binge drinking was similar to that used by Substance Abuse and Mental Health Association, we may have underestimated the number of binge drinkers, particularly among females, in our sample. In addition, participants could have consumed up to four drinks (56g ethanol) per occasion frequently and be classified as nonbingers. Residual confounding may be an issue because it is possible that unknown or unmeasured confounders of the association of interest were not taken into account. Finally, we could not assess whether a cumulative dose of alcohol over time (e.g., two drinks per day for one week) has the same effect on SBP as consuming an equivalent amount of alcohol in high doses on one or more single occasions (e.g., seven drinks on each of 2 days). Specifically, is it the cumulative dose over time that results in higher risk or is a high dose of alcohol on a single occasion riskier in terms of SBP?

If our findings are replicated, it might be that frequency of binge drinking in young adults is associated with the development of hypertension. More than one-fifth of monthly binge drinkers and almost one-quarter of weekly binge drinkers in our sample met the criterion for a diagnosis of prehypertension, a condition that frequently progresses to hypertension [38]. Most hypertension screening and treatment guidelines are based on studies conducted in middle-aged and older populations. Above normal BP in young adult men is significantly related to increased all-cause coronary heart and cardiovascular disease [39], whereas isolated systolic hypertension (i.e., SBP > 140 with diastolic BP $<90$ ) in young and middle adulthood increases the 31-year risk of developing cardiovascular disease and of death from coronary heart disease [40]. Because drinking patterns are modifiable, our findings may eventually have implications for clinical and preventive interventions. Health care practitioners who monitor BP in young adults should inquire about binge drinking, especially when elevated BP is found and counsel patients that binging is associated with increased SBP. From a public health perspective, although the dangers of binging in terms of intoxication, driving, safety, and addiction are well known, higher SBP may need to be added as a possible consequence of binge drinking in public health campaigns.

\section{Funding Sources}

The NDIT study was supported by the Canadian Cancer Society (grant numbers 010271, 017435 to J.L. O'Loughlin). Jennifer O'Loughlin holds a Canada Research Chair in the Early Determinants of Adult Chronic Disease. Erin O'Loughlin is supported by a doctoral fellowship from the Fonds de recherche Santé du Québec and a fellowship from CIHR in Population Intervention for Chronic Disease Prevention. The funding sources had no role in the conception, design or conduct of the study, or the writing of or decision to publish this article.

\section{References}

[1] Puddey IM, Beilin LJ. Alcohol is bad for blood pressure. Clin Exp Pharmacol Physiol 2006;33:847-52.

[2] Yoshita K, Miura K, Morikawa Y, et al. Relationship of alcohol consumption to 7-year blood pressure change in Japanese men. J Hypertens 2005;23: 1485-90.

[3] Chen L, Smith GD, Harbord RM, Lewis SJ. Alcohol intake and blood pressure: A systematic review implementing a Mendelian randomization approach. PloS Med 2008;5:e52.

[4] Fuchs FD, Chambless LE, Whelton PK, et al. Alcohol consumption and the incidence of hypertension: The atherosclerosis risk in communities study. Hypertension 2001;37:1242-50.

[5] Sesso HD, Cook NR, Buring JE, et al. Alcohol consumption and the risk of hypertension in women and men. Hypertension 2008;51:1080-7.

[6] Corrao G, Bagnardi V, Zambon A, La Vecchia C. A meta-analysis of alcohol consumption and the risk of 15 diseases. Prev Med 2004;38:613-9.

[7] Dyer AR, Cutter GR, Liu K, et al. Alcohol intake and blood pressure in young adults: The CARDIA study. J Clin Epidemiol 1990;43:1-13.

[8] Brummett BH, Babyak MA, Siegler IC, et al. Systolic blood pressure, socioeconomic status, and biobehavioral risk factors in a nationally representative US young adult sample. Hypertension 2011;58:161-6. 
[9] Marmot MG, Elliott P, Shipley MJ, et al. Alcohol and blood pressure: The INTERSALT study. BMJ 1994;308:1263-7.

[10] Substance Abuse and Mental Health Services Administration. Results from the 2011 National Survey on Drug Use and Health: Summary of national findings; 2012. Available at: http://www.samhsa.gov/data/NSDUH/ 2011SummNatFindDetTables/Index.aspx. Accessed April 18, 2013.

[11] Pajak A, Szafraniec K, Kubinova R, et al. Binge drinking and blood pressure: Cross-sectional results of the HAPIEE study. PLoS One 2013;8:e65856.

[12] Adlaf EM, Begin P, Sawka E, eds. Canadian Addiction Survey (CAS): A National Survey of Canadians' Use of Alcohol and Other Drugs: Prevalence of Use and Related Harms: Detailed Report. Ottawa: Canadian Centre on Substance Abuse; 2005. Available at: http://www.ccsa.ca/Resource\% 20Library/ccsa-004028-2005.pdf\#search=Canadian\%20Addiction\%20Survey\% 202005\%20Adlaf. Accessed April 10, 2013.

[13] National Institute on Alcohol Abuse and Alcoholism. What is a standard drink?. Available at: http://www.niaaa.nih.gov/alcohol-health/overviewalcohol-consumption/standard-drink. Accessed February 28, 2015.

[14] Kanny D, Liu Y, Brewer RD, et al. Vital signs: Binge drinking prevalence frequency, and intensity among adults-United States, 2010. MMWR Morb Mortal Wkly Rep 2012;61:14-9.

[15] O'Loughlin J, Dugas EN, Brunet J, et al. Cohort profile: The Nicotine Dependence in Teens (NDIT) study. Int J Epidemiol 2015;44:1537-46.

[16] Beevers DG. Epidemiological, pathophysiological and clinical significance of systolic, diastolic and pulse pressure. J Hum Hypertens 2004;18:531-3.

[17] Izzo JL Jr, Levy D, Black HR. Clinical advisory statement. Importance of systolic blood pressure in older Americans. Hypertension 2000:35:1021-4.

[18] Strandberg TE, Pitkala K. What is the most important component of blood pressure: Systolic, diastolic or pulse pressure? Curr Opin Nephrol Hypertens 2003;12:293-7.

[19] Labarthe DR. Project Heartbeat! Blood pressure manual of operations. Houston, TX: University of Texas Health Science Center at Houston; 1992.

[20] Parati G, Mancia G. Assessing the white-coat effect: Which blood pressure measurement should be considered? J Hypertens 2006;24:29-31.

[21] Garrison RJ, Kannel WB, Stokes J, Castelli WP. Incidence and precursors of hypertension in young adults: The Framingham Offspring Study. Prev Med 1987; 16:235-51.

[22] Dawson DA, Grant BF, Stinson FS, Chou PS. Another look at heavy episodic drinking and alcohol use disorders among college and noncollege youth. I Stud Alcohol 2004;65:477-88.

[23] Steffens AA, Moreira LB, Fuchs SC, et al. Incidence of hypertension by alcohol consumption: Is it modified by race? J Hypertens 2006;24:1489-92.

[24] Calhoun HM, Hemingway H, Poulter NR. Socio-economic status and blood pressure: An overview analysis. J Hum Hypertens 1998;12:91-110.
[25] Wellman RJ, Contreras GA, Dugas EN et al. Determinants of sustained binge drinking in young adults. Alcohol Clin Exp Res 2014;38:1409-15.

[26] Al-Safi SA. Does smoking affect blood pressure and heart rate? Eur J Cardiovasc Nurs 2005;4:286-9.

[27] Maximova K, O’Loughlin J, Paradis G, et al. Declines in physical activity and higher systolic blood pressure in adolescence. Am J Epidemiol 2009;170: 1084-94.

[28] Mooney SJ, Baecker A, Rundle AG. Comparison of anthropometric and body composition measures as predictors of components of the metabolic syndrome in a clinical setting. Obes Res Clin Pract 2013;7:e55-66.

[29] Evers SE, Hooper MD. Dietary intake and anthropometric status of 7 to 9 year old children in economically disadvantaged communities in Ontario. J Am Coll Nutr 1995;14:595-603.

[30] Bélanger M, O’Loughlin J, Karp I, et al. Physical activity fluctuations and body fat during adolescence. Pediatr Obes 2012;7:73-81.

[31] Institute for Digital Education. Regression diagnostics. Chapter 2 in Regression with SPSS, Los Angeles: UCLA. Available at: http://www.ats.ucla. edu/stat/spss/webbooks/reg/chapter2/spssreg2.htm. Accessed March $12,2015$.

[32] Stevens JP. Outliers and influential data points in regression analysis Psychol Bull 1984;95:334-44.

[33] Weisberg S. Applied linear regression. New York: Wiley; 1980.

[34] Cook RD. Detection of influential observations in linear regression. Technometrics 1977; 19:15-8.

[35] Chobanian AV, Bakris GL, Black HR, et al. The seventh report of the joint national committee on prevention, detection, evaluation, and treatment of high blood pressure: The JNC 7 report. JAMA 2003;289:2560-72.

[36] Zucker RA. Anticipating problem alcohol use developmentally from childhood into middle adulthood: What have we learned? Addiction 2008; 103(Suppl 1):100-8.

[37] National Institute on Alcohol Abuse and Alcoholism. Drinking levels defined. Available at: http://www.niaaa.nih.gov/alcohol-health/overviewalcohol-consumption/moderate-binge-drinking. Accessed July 4, 2015.

[38] Vasan RS, Larson MG, Lelp EP, et al. Assessment of frequency of progression to hypertension in nonhypertensive participants in the Framingham Heart Study: A cohort study. Lancet 2001;358:1682-6.

[39] Miura K, Daviglus ML, Dyer AR, et al. Relationship of blood pressure to 25 year mortality due to coronary heart disease, cardiovascular diseases, and all causes in young adult men: The Chicago heart association detection project in industry. Arch Intern Med 2001;161:1501-8.

[40] Yano Y, Stamler J, Garside DB, et al. Young and middle-aged adults and 31year risk for cardiovascular mortality: The Chicago heart association detection project in industry study. J Am Coll Cardiol 2015;65:327-35. 